\title{
GALECTIN-3 EXPRESSION IN THYROID TUMORS
}

\author{
Mira Siderova ${ }^{1}$, Kiril Hristozov' ${ }^{1}$ Ivan Krasnaliev ${ }^{2}$, Radoslav Radev ${ }^{3}$, Rumen Nenkov ${ }^{3}$ \\ ${ }^{1}$ Department of Internal Diseases, Faculty of Medicine, Medical University of Varna \\ ${ }^{2}$ Department of General and Clinical Pathology, Forensic Medicine and Deontology, \\ Faculty of Medicine, Medical University of Varna \\ ${ }^{3}$ Department of Surgery, Faculty of Medicine, Medical University of Varna
}

\begin{abstract}
AIM: The aim of this paper is to evaluate the expression of Galectin-3 in benign and malignant thyroid nodules and to assess its diagnostic value.

MATERIALS AND METHODS: Immunohistochemical analysis of Galectin-3 expression was performed on 64 surgically removed thyroid nodules, including 38 carcinomas (13 papillary, 2 tall cell variants, 4 lymph node metastases from papillary carcinoma, 6 follicular variants of papillary carcinoma (FVPTC), 4 anaplastic, 5 follicular and 4 Hürthle cell carcinomas), as well as 26 benign lesions ( 10 follicular adenomas, 5 Hürthle cell adenomas, 11 nodular goiters with surrounding normal thyroid tissue).

RESULTS: We found strong and diffuse Galectin-3 expression in all malignant lesions except for one case of FVPTC and one follicular carcinoma. Normal thyrocytes and the majority of the benign lesions were negative for Galectin-3. This molecular marker was expressed in the cytoplasm as well as in the nuclei of follicular cells. A statistical analysis determined the sensitivity $(94.7 \%)$, specificity $(69.2 \%)$, PPV (81.8\%), NPV $(90 \%)$, and accuracy $(83 \%)$ of Galectin-3.

CONCLUSION: Our findings suggest that the immunohistochemical expression of Galectin-3 might contribute to a differential diagnosis between malignant and benign thyroid nodules, including those with follicular architecture.
\end{abstract}

Keywords: Galectin-3, immunohistochemistry, thyroid carcinoma, thyroid nodules

Address for correspondence:

Mira Siderova

Clinic of Endocrinology

UMHAT "St.Marina" Varna

1 Hr.Smirnenski Blvd

9010 Varna

e-mail:mirasiderova@abv.bg

Received: June 29, 2016

Accepted: August 16, 2016

\section{INTRODUCTION}

Galectin-3 is a beta-galactoside binding polypeptide belonging to the lectin family and is normally present in human macrophages, neutrophils, Langerhans cells, and mast cells $(1,2)$. As a carbohydrate-binding molecule, Galectin-3 has high affinity to a large number of ligands - carcinoembryonic antigen (CEA), immunoglobulin E, laminin, and other mucins. Galectin-3 is involved in several biologi- 
cal and pathological processes including cell-cell and cell-matrix interaction, cell growth, neoplastic transformation, and apoptosis $(3,4)$.

In 1998, Fabio Orlandi was the first to investigate the thyroid expression of Galectin-3 in pre-surgical specimens obtained by fine needle aspiration biopsy (5). His study revealed selective expression of this protein in malignant tumors and no immunoreactivity in benign lesions as well as normal thyroid tissue (5). In recent years, many papers have proposed that Galectin-3 expression in the cytoplasm and nuclei of thyroid follicular cells could be considered a molecular marker of malignancy $(6,7)$. Galectin-3 regulates the cell cycle by inhibiting apoptosis and stimulating cell proliferation $(8,9)$. By inhibition of apoptosis, Galectin-3 ensures the survival of tumor cells. As an adhesion molecule, detected on the cell surface and in the extracellular matrix, it facilitates the formation of intravascular tumor microemboli and thus promotes tumor progression and metastasis (10).

The aim of this study was to investigate the immunohistochemical expression of Galectin-3 in benign and malignant thyroid nodules, and to assess its diagnostic value in determining the benign or malignant nature of various lesions, especially in lesions of follicular origin.

\section{MATERIALS AND METHODS}

Immunohistochemical analysis was performed on 64 formalin-fixed paraffin-embedded thyroid tissues from surgically resected thyroid nodules, including 38 carcinomas (13 classic papillary carcinomas, 2 tall cellvariants, 4 lymph node metastases from papillary carcinoma, 6 follicular variants of papillary carcinoma, 4 anaplastic carcinomas, 5 follicular carcinomas, 4 Hürthle cell carcinomas), as well as 26 benign lesions (10 follicular adenomas, 5 Hürthle cell adenomas, 11 nodular goiters in connection with surrounding normal thyroid tissue).

Four- $\mu \mathrm{m}$-thick sections were prepared on adhesive slides coated withpoly-L-lysine. After deparaffinization and rehydration, the specimens were incubated with hydrogen peroxide in order to reduce nonspecific background staining due to endogenous peroxidase. Heat-induced antigen retrieval was achieved in a hot water bath at $97^{\circ} \mathrm{C}$ for 20 minutes in citrate buffer. The next step was incubation with pri- mary antibody (against Galectin-3 dilution 1:50, Lab Vision). After rinsing four times in buffer, the slides were treated with detection complex, comprised of HRP Polymer, DAB Plus Substrate and Chromogen (Lab Vision). A present enzyme reaction, proved by chromogen staining, marked the antigen immunopositivity. The whole procedure was performed in a closed system -Autostainer Lab Vision 360, following step by step a computer protocol. Counterstaining was made with hematoxylin. Negative controls were obtained by omitting the primary antibody.

Galectin-3 was considered immunopositive if it showed cytoplasmic or cytoplasmic and nuclear expression. Isolated nuclear expression was categorized as negative. The immunostaining was evaluated using the following semiquantitative scale:

$\diamond(-)$ no reactivity or some epithelial cells $(<10 \%)$ with weak positivity.

$\diamond(+)$ focal reactivity, with weak immunostaining in 10 to $30 \%$ of the neoplastic cells.

$\diamond(++)$ moderate reactivity, 30 to $60 \%$ of the neoplastic cells show immunostaining.

$\diamond(+++)$ diffuse and strongly expressed positivity in more than $60 \%$ of the neoplastic cells.

\section{Statistical Analysis}

Histological diagnosis was considered the gold standard. Sensitivity of the assessed molecular marker was calculated on the basis of thyroid cancer detection using the formula [true positive/(true positive + false negative)]. Specificity was defined on the basis of benign lesions detection [true negative/(true negative + false positive)]. Positive and negative predictive values were calculated as [true positive/(true positive + false positive)] and [true negative/(true negative + false negative)], respectively. For diagnostic accuracy we used the following formula [(true positive + true negative)/(true positive + false positive + true negative+ false negative)].

\section{RESULTS}

The expression of Galectin-3 was moderate $(++)$ to strong and diffuse $(+++)$ in all malignant lesions with the exception of two cases of follicular variant of papillary carcinoma (FVPTC) and one follicular carcinoma (Table 1). The expression of this marker was in the cytoplasm as well as in the nuclei of follicular cells (Figures 1,2,3,4). 
Table 1. Results of immunohistochemical expression of Galectin-3 in each of the histological categories

\begin{tabular}{|c|c|c|c|c|c|}
\hline $\begin{array}{l}\text { Histological } \\
\text { diagnosis }\end{array}$ & $\begin{array}{l}\text { Number of } \\
\text { cases }\end{array}$ & $\begin{array}{l}\text { Galectin-3 } \\
\text { positivity }\end{array}$ & Focal $(+)$ & $\begin{array}{c}\text { Moderate } \\
(++)\end{array}$ & $\begin{array}{c}\text { Diffuse and } \\
\text { strong }(+++)\end{array}$ \\
\hline Papillary Ca & 13 & $13 / 13(100 \%)$ & 0 & 5 & 8 \\
\hline $\begin{array}{l}\text { Lymph node metastasis of } \\
\text { papillary carcinoma }\end{array}$ & 4 & $4 / 4(100 \%)$ & 0 & 1 & 3 \\
\hline $\begin{array}{l}\text { Follicular variant of papillary } \\
\text { carcinoma }\end{array}$ & 6 & $4 / 6(67 \%)$ & 0 & 2 & 2 \\
\hline Tall cell variant & 2 & $2 / 2(100 \%)$ & 0 & 1 & 1 \\
\hline Follicular carcinoma & 5 & $4 / 5(80 \%)$ & 0 & 1 & 3 \\
\hline Hürthle cell carcinoma & 4 & $4 / 4(100 \%)$ & 0 & 2 & 2 \\
\hline Anaplastic carcinoma & 4 & $4 / 4(100 \%)$ & & 3 & 1 \\
\hline Follicular adenoma & 10 & $2 / 10(20 \%)$ & 2 & 0 & 0 \\
\hline Hürthle cell adenoma & 5 & $3 / 5(60 \%)$ & 3 & 0 & 0 \\
\hline Nodular goiter & 11 & $3 / 11(27 \%)$ & 3 & 0 & 0 \\
\hline $\begin{array}{l}\text { Normal thyroid tissue sur- } \\
\text { rounding nodular goiter }\end{array}$ & 11 & $0 / 11(0 \%)$ & 0 & 0 & 0 \\
\hline
\end{tabular}

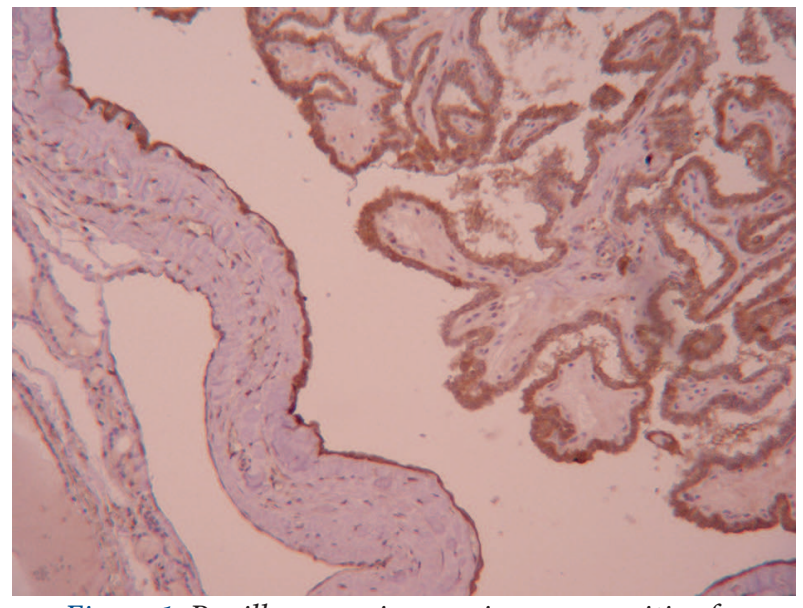

Figure 1. Papillary carcinoma, immunopositive for Galectin-3

Immunohistochemical analysis provided excellent visualization of capsular and vascular invasion (Figure 5), which was not so clear on routine histology with hematoxylin. Lymph node metastases of papillary carcinoma, as well as primary tumors with unfavorable prognosis (tall cell variant, Hürthle cell carcinoma and anaplastic carcinoma) were $100 \%$ positive for Galectin-3 (Figure 6).

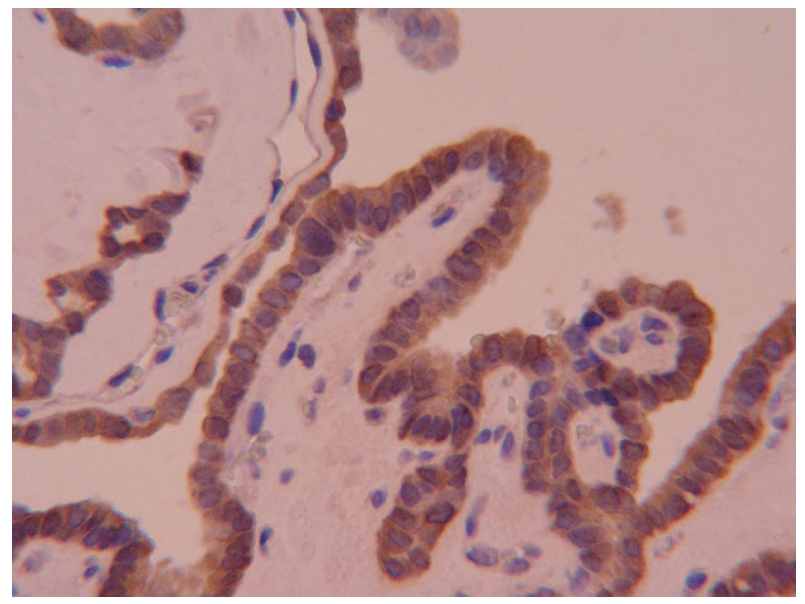

Figure 2. Papillary carcinoma, immunopositive for Galectin-3 - cytoplasmic and nuclear expression

Normal thyroid tissue surrounding hyperplastic benign nodules did not express Galectin-3. The majority of the benign lesions (follicular adenomas, Hürthle cell adenomas and nodular goiter) were negative for the examined molecular marker (Figure 7). The exceptions showed only focal and weak staining (+) for Galectin-3 (Figure 8), predominantly in areas of cystic degeneration and chronic inflammation. In four of these cases, weak immunopostivity was reg- 
Mira Siderova, Kiril Hristozov, Ivan Krasnaliev, Radoslav Radev, Rumen Nenkov

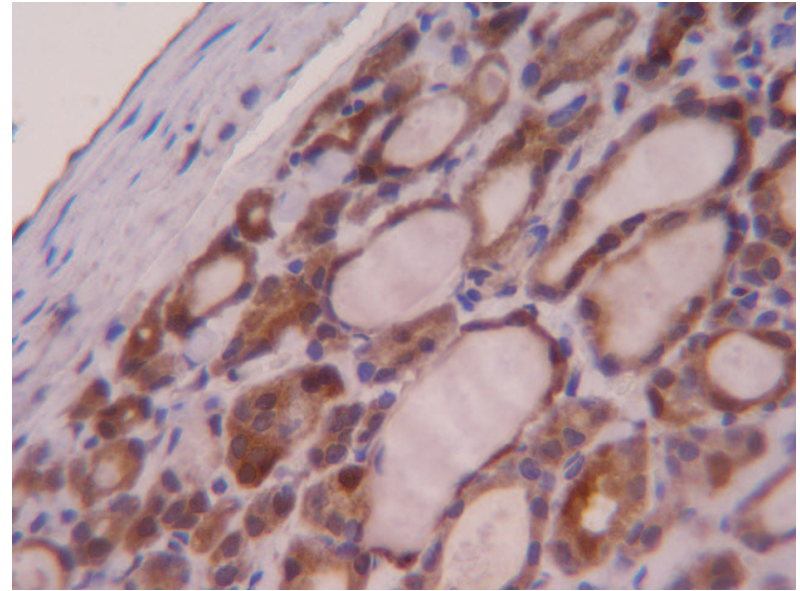

Figure 3. Follicular carcinoma, immunopositive for Galectin-3

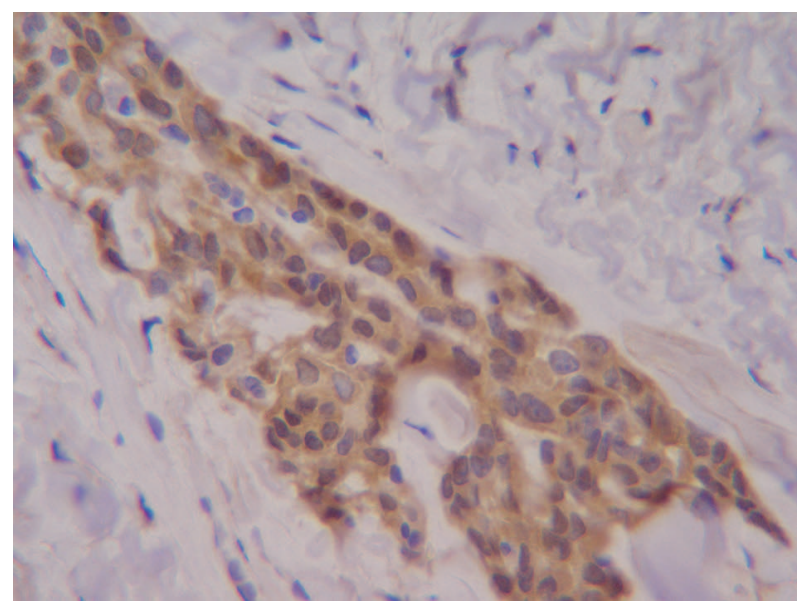

Figure 5. Capsular invasion of "tall cell" variant of papillary carcinoma with Galectin-3 immunohistochemistry

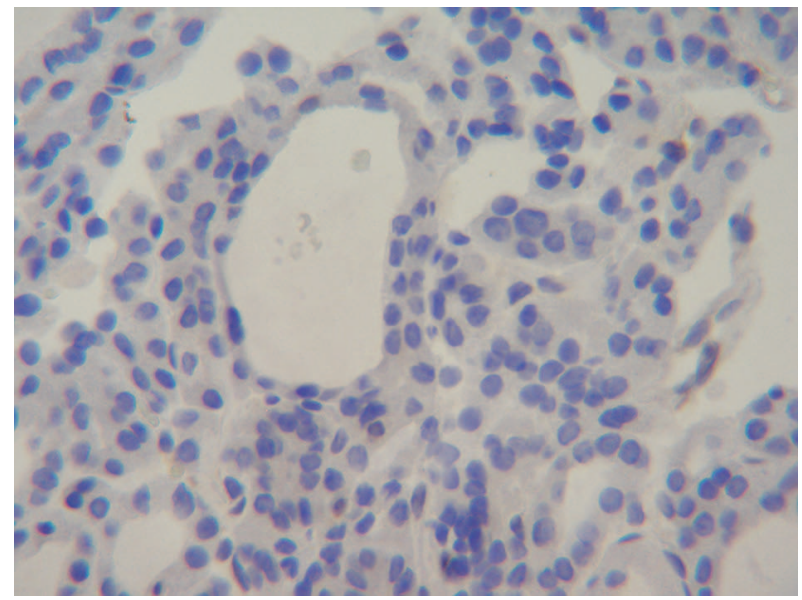

Figure 7. Follicular adenoma, immunonegative for Galectin-3



Figure 4. "Tall cell" variant of papillary carcinoma - Galectin-3 expression

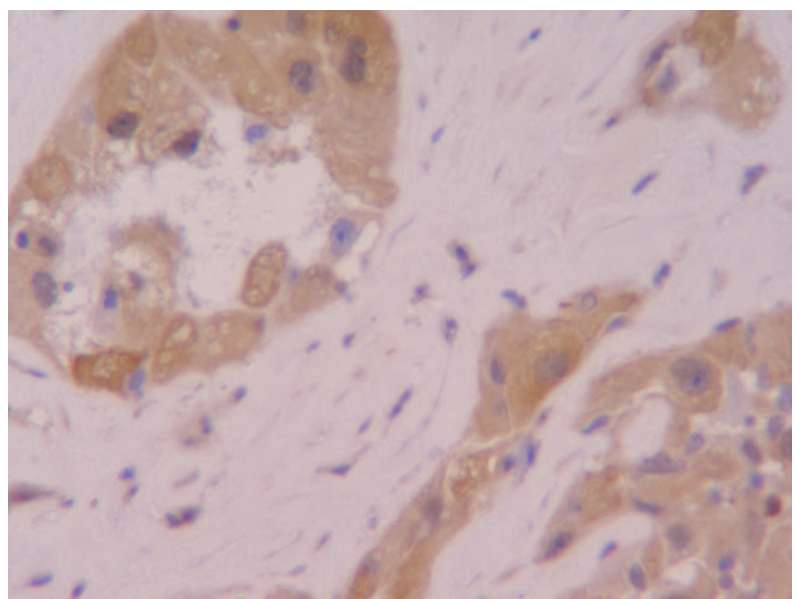

Figure 6. Anaplastic carcinoma, immunopositive for Galectin-3

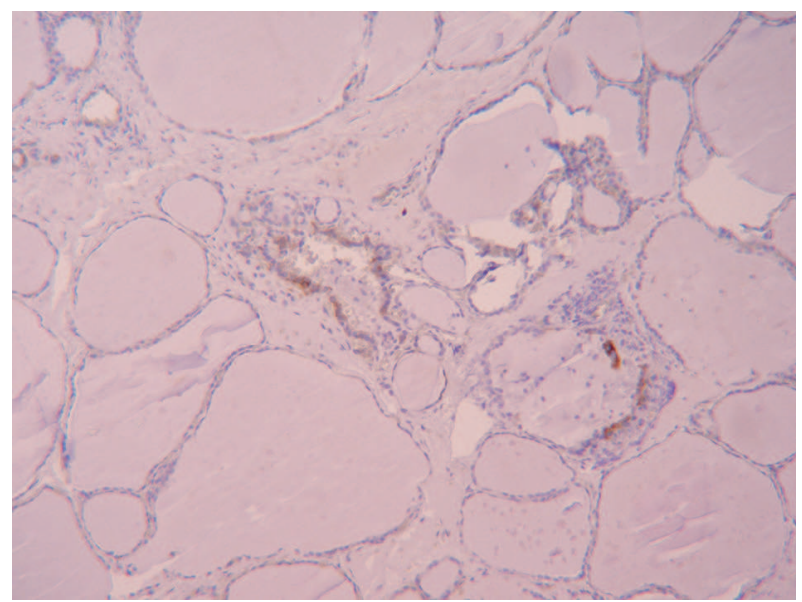

Figure 8. Nodular goiter with focal (+) staining gor Galectin-3 in areas of chronic inflammation 
istered in the place corresponding to preceding fine needle aspiration biopsy.

Statistical analysis of the diagnostic value of Galectin-3, used as a single marker for differentiation of malignant versus benign nodules, revealed sensitivity $94.7 \%$, specificity $69.2 \%$, PPV $81.8 \%$, NPV $90 \%$ and diagnostic accuracy $83 \%$.

\section{DISCUSSION}

Thyroid cancer is the most common endocrine malignancy, and more than 95\% of thyroid carcinomas originate from follicular epithelial cells (11). Papillary thyroid carcinoma (PTC) is the most common of the well-differentiated carcinomas, comprising $80-85 \%$ of thyroid cancers (12). In its classical variant it presents no difficulty in cytological and histological diagnosis due to its distinctive nuclear features - clear nuclei with hypodense chromatin, nuclear grooves and inclusions, as well as formation of neoplastic papillae and the presence of psammoma bodies (13). Immunohistochemistry offers diagnostic advantages in cases of cystic thyroid lesions, that can harbor occult papillary cancer (14), in less differentiated variants as tall cell, hobnail or columnar cell variants and in lymph metastases. Intrathyroidal microfoci of papillary carcinoma are better visualized by immunohistochemistry and distinguished from benign hyperplastic changes with papillation $(15,16)$. The diagnosis of microcarcinomas, especially below $5 \mathrm{~mm}$ and multifocality of the tumor is often clear after an immunohistochemical analysis. In two of our cases of papillary carcinoma (one classical and one follicular variant), additional microfoci of the carcinoma ( $2 \mathrm{~mm}$ and $3 \mathrm{~mm}$, respectively) were missed on routine histology but showed strong immunostaining for Galectin-3. We consider the immunohistochemical analysis a useful tool for proving the multifocality of the tumor, as well as for diagnosis of microcarcinomas, especially below $5 \mathrm{~mm}$.

Follicular variant of papillary thyroid carcinoma (FVPTC) represents the second most common variant of PTC after the classical one (4). Along with follicular architecture, it is characterized by nuclear features of PTC. Our results showed that FVPTC is mostly positive for Galectin-3 (67\%).

Follicular patterned lesions represent a cytological and histological challenge. They account for $20-30 \%$ of thyroid nodules and include the follow- ing histological categories: follicular adenoma, follicular adenoma with cytological atypia, follicular carcinoma and minimally invasive follicular carcinoma (17). For example, differentiation between follicular adenoma and minimally invasive follicular carcino$\mathrm{ma}$ is not possible preoperatively because it requires demonstration of capsular and/or vascular invasion on histology (17). Even the histological interpretation of what constitutes capsular and/or vascular invasion vary among pathologists (17). In these cases, immunohistochemistry for molecular markers that are differently expressed in benign and malignant nodules could be useful $(18,19,20)$. It visualizes well capsular invasion and improves diagnosis and treatment choice. The investigation of molecular markers and their preoperative application is mostly discussed and recommended in this category of follicular neoplasms hoping to subdivide these indeterminate lesions $(5,21,22)$. Our findings suggest that for a differentiation between follicular neoplasms (follicular carcinoma versus adenoma), Galectin-3 has relatively high sensitivity (80\%) and specificity (80\%). In the study of Ito et al., Galectin-3 expression significantly increased with the degree of vascular or capsular invasion of follicular tumors (23). Galectin-3 reactivity in suspicious adenoma should provoke a search for other features of malignancy including capsular or vascular invasion (15).

The nuclear atypia and polymorphism of oncocytic tumors does not correlate with their biological behavior (4). Preoperatively, it is not possible to distinguish Hürthle cell carcinoma from adenoma, the difference between which is the capsular invasion. Differential diagnosis of oncocytic (Hürthle cell) neoplasms includes malignant tumors as a follicular variant of papillary carcinoma with oncocytic changes, medullary carcinoma, as well as benign diseases like Hashimoto's thyroiditis with oxyphilic metaplasia (4). Our results show that the follicular variant of papillary carcinoma is mostly positive for Galectin-3.

In our study, normal thyroid tissue was immunonegative for Galectin-3. The majority of benign lesions (follicular adenomas, Hürthle cell adenomas and nodular goiter) were also negative for this marker. The exceptions showed only focal and weak staining (+), limited to areas of cystic degeneration, chronic inflammation and lymphocytic infiltration. 
Mira Siderova, Kiril Hristozov, Ivan Krasnaliev, Radoslav Radev, Rumen Nenkov

A number of previous studies report focal Galectin-3 expression in some follicular cells in Hashimoto's thyroiditis as well as degenerative parts of hyperplastic nodules (24). However, diffuse positivity in papillary carcinoma, FVPC and anaplastic cancer has diagnostic value $(15,25)$. The distribution and intensity of Galectin-3 staining are the most important and critical aspects of accurate interpretation $(4,24)$.

We observed Galectin-3 focal staining in 3 cases of nodular goiter, which had focal lymphocytic infiltrates and in 2 cases of follicular adenoma, which were showing signs of cytological atypia without any capsular invasion (Table 1). Studies including tumors classified as neoplasms of uncertain malignant potential report Galectin-3 expression pattern which is intermediate between adenoma and carcinoma (26). Its immunodetection in follicular adenomas with nuclear atypia without definite capsular invasion leads to the proposal of some authors that Galectin-3 may be extremely sensitive and early marker of malignant cell transformation $(27,28)$. However, future studies are needed to verify this hypothesis.

In conclusion, our findings suggest that immunohistochemical expression of Galectin-3 might contribute to differential diagnosis between malignant and benign thyroid nodules, including those with follicular architecture. It order to improve the specificity it could also be combined with other molecular markers as an immunohistochemical panel (29). Furthermore, this molecular marker could be applied preoperatively in the analysis of FNAB specimens in order to increase the diagnostic accuracy of routine cytology, especially in the category of "indeterminate lesions".

\section{REFERENCES}

1. Barondes SH, Cooper DN, Gitt MA, Leffler H. Galectins: structure and function of a large family of animal lectins. J BiolChem 1994; 269: 20807-20810

2. Kovacs RB, Földes J, Winkler G, Bodo M, Sapi Z. The investigation of galectin- 3 in diseases of the thyroid gland. Eur J Endocrinol 2003; 149: 449-453

3. Krzeslak A, Lipinska A. Galectin-3 as a multifunctional protein. Cell MolBiol Lett 2004; 9: 305-28.

4. Fischer S, Asa SL. Application of immunohistochemistry to thyroid neoplasms. Arch Pathol Lab Med 2008; 132: 359-372
5. Orlandi F, E Saggiorato, G Pivano, Puligheddu B, Termine A, Cappia S, De Giuli P, Angeli A. Galectin-3 as a presurgical marker of human thyroid carcinoma. Cancer Research 1998; 58: 3015-3020

6. Bartolazzi A, Orlandi F, Saggiorato E, Volante M, Arecco F, Rossetto R, Palestini N, Ghigo E, Papotti $\mathrm{M}$, Bussolati G et al. Galectin-3-expression analysis in the surgical selection of follicular thyroid nodules with indeterminate fine-needle aspiration cytology: a prospective multicentre study. The Lancet Oncology 2008; 9: 543-549

7. Herrmann ME, LiVolsi VA, Pasha TL, Roberts SA, Wojcik EM, Baloch ZW. Immunohistochemical expression of galectin-3 in benign and malignant thyroid lesions. Arch Pathol Lab Med 2002; 126: 710-713.

8. Lin HM, Moon B, Yu F, KimHR. Galectin-3 mediates geninstein-induced G2/M arrest and inhibits apoptosis. Carcinogenesis 2000; 21: 1941-1945

9. Yang RY, Hsu DK, Liu FT. Expression of Galectin-3 modulates T-cell growth and apoptosis. Immunology 1996; 93: 6737-6742

10. Inohara H, Akahani S, Koths K, Raz A. Interactions between Galectin-3 and Mac-2 binding protein mediate cell-cell adhesion. Cancer Research 1996; 56: 4530-4534

11. Hundahl SA, Fleming ID, Fremgen AM, et al. A National Cancer Data Base report on 53,856 cases of thyroid carcinoma treated in the U.S., 19851995. Cancer. 1998; 83:2638-2648.

12. Grodski S, Delbridge L. An update on papillary microcarcinoma. CurrOpinOncol 2008; 21: 1-4

13. Bomeli SR, LeBeau SO, Ferris RL. Evaluation of a thyroid nodule. OtolaryngolClin North Am 2010; 43: 229-238

14. Papotti M, Volante M, Saggiorato E, Deandreis D, Veltri A, Orlandi F. Role of Galectin-3 immunodetection in the cytological diagnosis of thyroid cystic papillary carcinoma. Eur J Endocrinol 2001; 147: 515-521

15. Cheung CC, Ezzat S, Freeman JL, Rosen IB, Asa SL. Immunohistochemical diagnosis of papillary thyroid carcinoma. Mod Pathol 2001; 14: 338-342

16. Savin S, Cvejic D, Isic T, Paunovic I, Tatic $S$, Havelka M. Thyroid peroxidase and Galectin-3 immunostaining in differentiated thyroid carcinoma: diagnostic usefulness and clinicopathological correlation. Hum Pathol 2008; 39: 1656-1663 
17. Baloch ZW, Livolsi VA. Follicular-patterned lesions of the thyroid: the bane of the pathologist. Am J ClinlPathol 2002; 117: 143-150

18. Saggiorato E, Cappia S, Guili P, Mussa A, Pancani G, Caraci P, Angeli A, Orlandi F. Galectin-3 as a presurgicalimmunocytodiagnostic marker of minimally invasive follicular thyroid carcinoma. J ClinEndocrinolMetab 2001; 86: 5152-5158

19. Grogan RH, Mitmaker EJ, Clark OH. The evolution of biomarkers in thyroid cancer-from mass screening to a personalized biosignature. Cancers 2010; 2: 885-912

20. Nakamura N, Erickson LA, Jin L, Kajita S, Zhang H, Qian X, Rumilla K, Lloyd RV. Immunohistochemical separation of follicular variant of papillary thyroid carcinoma from follicular adenoma. EndocrPathol 2006; 17: 213-223

21. Zosin I, Cornianu M, Golu I, Balas M. Usefulness of immunohistochemistry in the diagnosis of nodular thyroid disease. Acta Endo (Buc) 2007; 3: 437- 450

22. Saleh HA, Jin B, Barnwell J, Arzohaili O. Utility of immunohistochemical markers in differentiating benign from malignant follicular-derived thyroid nodules. DiagnPathol, 2010; 5:9

23. Ito $\mathrm{Y}$, Yoshida $\mathrm{H}$, Tomoda $\mathrm{C}$, et al. Galectin-3 expression in follicular tumours: an immunohistochemical study of its use as a marker of follicular carcinoma. Pathology. 2005;37:296-298

24. Ardito G, Revelli L, Boninsegna A, Sgambato A, Moschella F, Marzola MC, Giustozzi E, Avenia N, Castelli M, Rubello D. Immunohistochemical evaluation of inflammatory and proliferative markers in adjacent normal thyroid tissue in patients undergoing total thyroidectomy: results of a preliminary study. Journal of experimental and clinical cancer research 2010; 17: 29-77

25. Tatic S. Histopathological and immunohistochemical features of thyroid cancer. Arch Oncol 2003; 11: 173-174

26. Prasad ML, Pellegata NS, Huang Y, Nagaraja NH, Chapelle A, Kloos RT. Galectin-3, fibronectin-1, CITED-1, HBME1 and cytokeratin-19 immunohistochemistry is useful for the differential diagnosis of thyroid tumors. Modern Pathology 2005; 18: 48-57

27. Asa SL. The role of immunohistochemical markers in the diagnosis of follicular-patterned lesions of the thyroid.EndocrPathol 2005; 16: 295-309
28. Coli A, Bigotti G, Zucchetti F, Negro F, Massi F. Galectin-3, a marker of well-diffentiated thyroid carcinoma, is expressed in thyroid nodules with cytological atypia. Histopathology 2002; 40: 80-87

29. Siderova M, Hristozov K, Krasnaliev I, Softova E, Boeva E. Application of immunohistochemical markers in the differential diagnosis of thyroid tumors. ActaEndocrinologica, 2013, 9: 41-52 